\title{
Fotografía y antropología: los inicios de una relación fructífera
}

\author{
JOAN NARANJO \\ Comisario de exposiciones y \\ Miembro de la comisión asesora del Departamento de Fotografía \\ del Museu Nacional d'Art de Catalunya
}

La fotografía ha estado frecuentemente asociada a la imagen que se refleja en el espejo, de hecho éste es el único referente con que el hombre pudo asociar el nuevo y revolucionario invento que fue tachado de “invención del diablom. Ernest Lacan ${ }^{1}$ en su libro Esquisses Photographiques, al hacer referencia a la invención de la fotografía escribió: "Fijaba la imagen fugitiva del espejo. Era un prodigio que no se explicaba, pero que era necesario creer ${ }^{2}$. Lewis Munford cita la invención del espejo como "el inicio de la biografía introspectiva en el estilo moderno, es decir no como un medio de edificación sino como una pintura del yo [...] El yo del espejo se corresponde al mundo físico que fue expuesto a la luz por las ciencias naturales en la misma época; era el yo abstracto, sólo una parte del yo real, la parte que uno puede separar del fondo de la naturaleza y de la presencia influyente de los demás hombres" ${ }^{3}$. Estas cualidades que Munford atribuye al espejo son extrapolables a la fotografía y de ahí el gran interés que suscitó su invención ${ }^{4}$, que inicialmente fascinó más a los medios científicos que a los artísticos ', ya que la asociaron a 'objetividad', 'fidelidad', 'veracidad' en definitiva a un 'perfecto documento'.

La interrelación entre la fotografía y la antropología se da desde el nacimiento de la fotografía. Este hecho es muy comprensible, ya que la

1 Ernest LaCAN, fue crítico de la revista fotográfica francesa La Lumière y su libro, Esquisses Photographiques (Paris: Grassat editeur y A. Gaudin et Frére, 1856), es uno de los primeros donde se tratan aspectos como la crítica y la estética fotográfica.

2 Ibid.

3 Lewis Munford, Técnica y Civilización (Madrid: Alianza Editorial, 1982).

4 En un breve plazo de tiempo se publicaron numerosas ediciones y traducciones a diferentes idiomas del manual de Daguerre.

5 Para ciertos sectores artísticos la fotografía era sólo una imagen realizada de forma mecánica, que surgía automáticamente y donde no intervenía el artista en el proceso creativo. 
fotografía fue tomada como el medio de representación más 'perfecto' y 'objetivo' de la época. Sabin Berthelot, que habitó durante un largo periodo de tiempo en las islas Canarias, fue uno de los primeros naturalistas en utilizar la imagen fotográfica para sus investigaciones antropológicas ${ }^{6}$. En su monumental obra Histoire Naturelle des Îles Canariens (1835-50) que publicó junto a P. Barker Weeb, reprodujo dos retratos: "Descendant de Canarien" (fig. 1) y "Habitant de l'île de Palma". Estos dos retratos son reproducidos en el tomo de Ethnograbie et annales de la conquête, publicado en 1842. Berthelot seguramente comisionó al daguerrotipista Bisson Fils para que realizara estos retratos, que luego aparecieron reproducidos en la obra antes citada como litografías sacadas a partir de daguerrotipos. E. Thiessons fue otro de los primeros fotógrafos que realizó, en París, en 1844, una serie de daguerrotipos de marcado interés antropológico, entre los cuales se conserva algún ejemplar antropométrico de varios tipos de la tribu de los botocudos (Brasil). También son de destacar, entre los primeros intentos, los daguerrotipos que realizó Jules Itier, jefe de la misión comercial en la China, las Indias y Oceanía. Itier realizó en China, entre 1843 y 1844 , una serie de daguerrotipos que son un excepcional documento de las primeras fotografías de viaje. El capitán de fragata Gillain durante su periplo (1846-1848) por la costa oriental de África fotografió a algunos miembros del pueblo somalí, fotografías que posteriormente publicó en el libro titulado Voyage à la Côte Orientale d'Afrique (1857). El fotógrafo J. T. Zealy realizó en 1850, comisionado por Louis Agassiz, una serie de daguerrotipos sobre los esclavos negros de Carolina del Sur, para demostrar la inferioridad de la raza negra.

No obstante, durante la primera década de la invención de la fotografía, estas experiencias fueron aisladas. Fue con los viajes de las primeras expediciones fotográficas cuando se empezó a producir una mayor cantidad de imágenes de contenido etnográfico, aunque su finalidad original fuera de carácter comercial, documental, política, científica, etc.

Las bases teóricas se dan desde los dos ámbitos: el fotográfico y el antropológico. Ernest Lacan en su libro de 1856, que ya hemos citado anteriormente, hace referencia a los trabajos sobre fotografía y antropología:

Si la fotografía toma al museo de Historia Natural sus riquezas para popularizarlas, la historia natural, puede, a cambio, añadir preciosos especímenes a sus galerías. El estudio de las razas humanas es una de las que interesan más a la ciencia. ¡Cuántos tipos no ha reunido el fotógrafo retratista en sus portafolios! [...] se hace fotografía en todos los países del mundo; los retratos realizados en la India,

6 Ver Juan NARANJo, "Photography and Ethnography in Spain", History of Photography, 21, 1 (1997). 


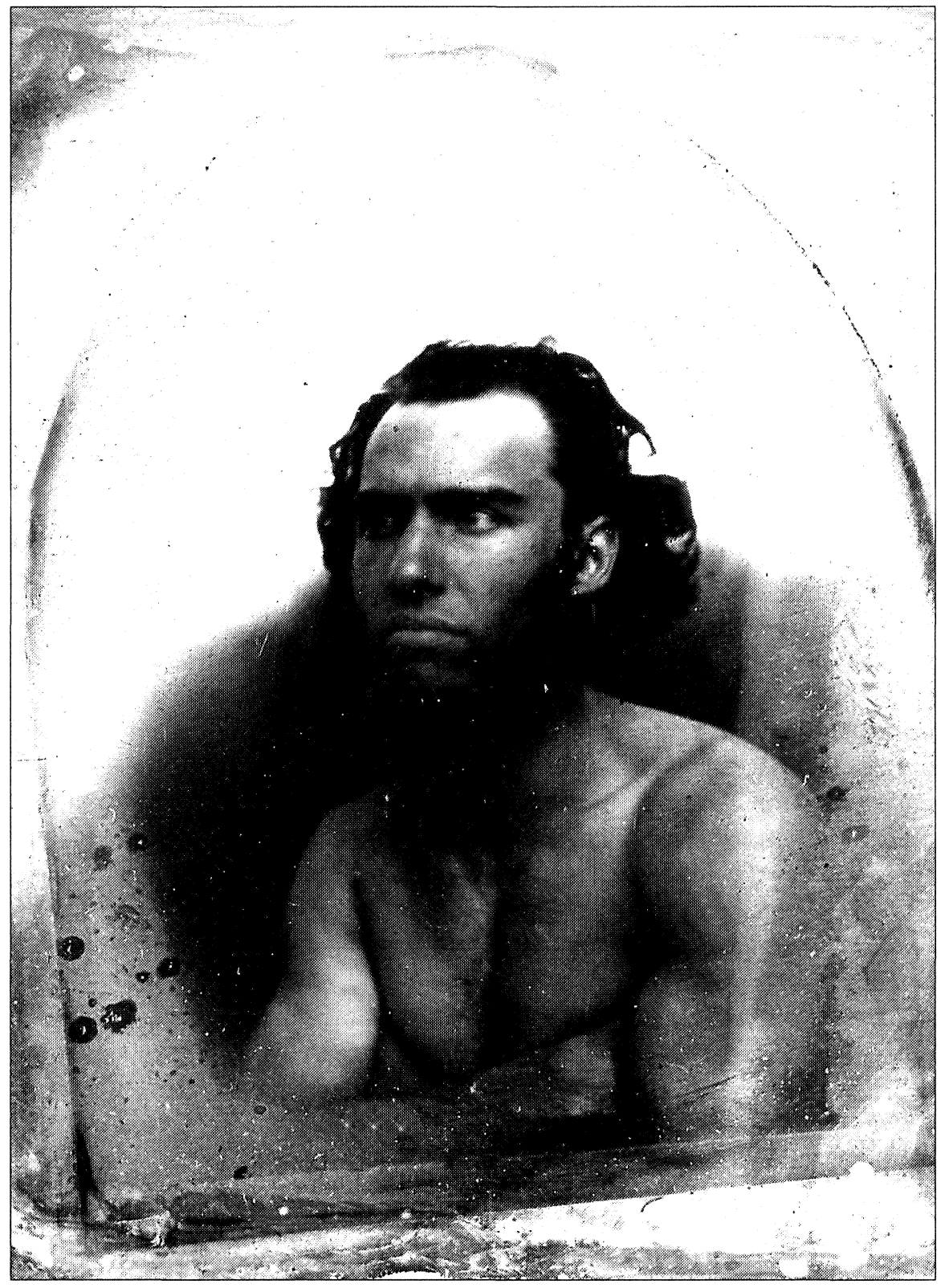

FIG. 1.-Collection S. Berthelot. Musée de l'Homme. París. 
en África, en América, en Rusia en todas partes bastarán para componer una amplia colección de tipos de razas vivas [...] En cuanto a las razas que han desaparecido M. Rosseau ${ }^{7}$ ha tenido el cuidado de reproducir los cráneos que están en manos de los antropólogos ${ }^{8}$.

Los fotógrafos Mayer \& Pierson escribieron un interesante texto sobre la función que tenía que desempeñar la utilización de la fotografía al servicio de la antropología, sobre todo en los museos:

Cuando se recorren las galerías antropológicas del museo, es un vistazo suficiente para comprender qué servicios dará la fotografía al estudio de las razas humanas. Los moldes de yeso que se encuentran en el museo reproducen con exactitud las formas, pero les falta aquello que caracteriza sobre todo al hombre, la fisionomía. En los retratos, bajo estas caras más o menos bestiales, hay vida y siempre un rayo de inteligencia, en los yesos sólo tipos inertes, sin vida, sin alma. Este es uno de los menores servicios rendidos por la fotografía a la civilización, el de haber permitido un día a la ciencia recoger bastantes tipos auténticos para poder estudiar las razas humanas .

En estos textos escritos desde el punto de vista de los teóricos del ámbito fotográfico, se hace patente el interés que hay hacia el mundo científico y las ventajas que la fotografía puede aportar a los estudios de las diferentes razas humanas. Las posibilidades que estos teóricos vieron en la aplicación de la fotografía al ámbito antropológico estaban unidas principalmente a su 'objetividad', al 'realismo' y la gran capacidad que les proporcionaba este medio para poder confeccionar un mapa de los diferentes tipos raciales. No obstante, todas las cuestiones que hacen referencia a la sistematización, a la racionalización de los datos para su posterior análisis fueron obviadas. La metodología para la interrelación entre la fotografía y la antropología es aportada a través de los textos publicados por las sociedades científicas o, como veremos más adelante, por los antropólogos físicos.

En 1854, la British Association for the Advancement of Science (BAAS) publicó el Manual of Etbnological Inquiry, en él se establecían una serie de instrucciones para que los cónsules, políticos, residentes y viajeros pudiesen recopilar información de forma estandarizada sobre los diferentes tipos raciales, medidas, usos, costumbres, y se recomendaba la obtención de retratos individuales mediante algún procedimiento fotográfico. A

7 Louis Rousseau fue el antecesor de J. Potteau en el Museo de Historia Natural de París y publicó junto a A. Devéria, La Pbotographie Zoologique, 1853.

8 Ernest LaCAN, op. cit.

9 MAYER \& Louis PIERSON, La Photographie (Paris: Librairie L. Hachette, 1862). 
través de la lectura de dicho manual, se puede observar fácilmente la preocupación de los antropólogos por la extinción de algunas variedades de la raza humana - ya que el efecto de la colonización en algunos casos fue devastador-y el interés que despertó el estudio de los nuevos pueblos recientemente sometidos. El interés por la preservación y el análisis del 'otro' fue una constante durante el siglo xIx. En otro manual publicado en 1874 por la BAAS, Notes and Queries on Anthropology, se siguió mostrando la misma preocupación por la extinción de ciertas razas, pero conceptualmente hay un salto sustancial, ya que se establece que es imperativo estudiarlos antes de que sean exterminados o reducidos al estándar de los usos y maneras europeos (fig. 2).

La publicación del Manual of Ethnological Inquiry coincide con un periodo de gran expansión colonial; los viajes por cuestiones mercantiles, políticas o científicas se sucedieron. Al mismo tiempo, en el terreno fotográfico, con la invención en 1851 del colodión húmedo por Frederick Scott Archer, se simplificó notablemente el procedimiento fotográfico y aumentó el numero de fotógrafos profesionales y aficionados. Durante las décadas siguientes, un gran número de fotógrafos recorrieron el mundo dispuestos a inventariarlo con sus fotografías, sobre todo los lugares más exóticos y remotos de las colonias. Entre las principales expediciones fotográficas cabe destacar las de Auguste Salzmann (1854), James T. Barclay (1855), James Robertson y Felice Beato (1856), Wilhelm Hammerschmidt (1860), Antonio Beato (1862), Francis Bedford (1862), que trabajaron en Egipto, Siria y Palestina. En la India, Samuel Bourne (1860) y John Murray (1863); en China, John Thomson (1868); en Brasil, A. Frisch (1865); en Java, Walter Woodbury (1865); en Groenlandia, Dunmore y Critcherson (1869); en América del Sur, Rafael Castro Ordónez (1862); en Méjico, Desire Charnay, (1857); en Argelia, F. J. A. Moulain (1856), etc ${ }^{10}$.

La mayor parte de estos observadores, en sus diferentes viajes, realizaron fotografías de un marcado interés 'antropológico' y 'etnográfico', aunque carecían de una base científica. Sus imágenes, tomadas bajo un prisma documental y a veces artístico, nos revelan las maravillas del mundo, aún muy poco conocidas, así como la arquitectura, usos, costumbres, tipos, oficios; en definitiva, las formas de vida de estas civilizaciones, tan lejanas como 'exóticas'.

F. J. A. Moulain partió en 1856 para Argelia, donde realizó una extensa documentación sobre las diferentes etnias (fig. 3), los 'tipos', las costumbres, los monumentos, etc. A su regreso a París, al cabo de dieciocho

10 Para una mayor información sobre la fotografía de viajes ver: Rainer FABIAN \& Hans Cristian ADAM, Masters of Early Travel Pbotograpby (London: Thames and Hudson, 1983). 


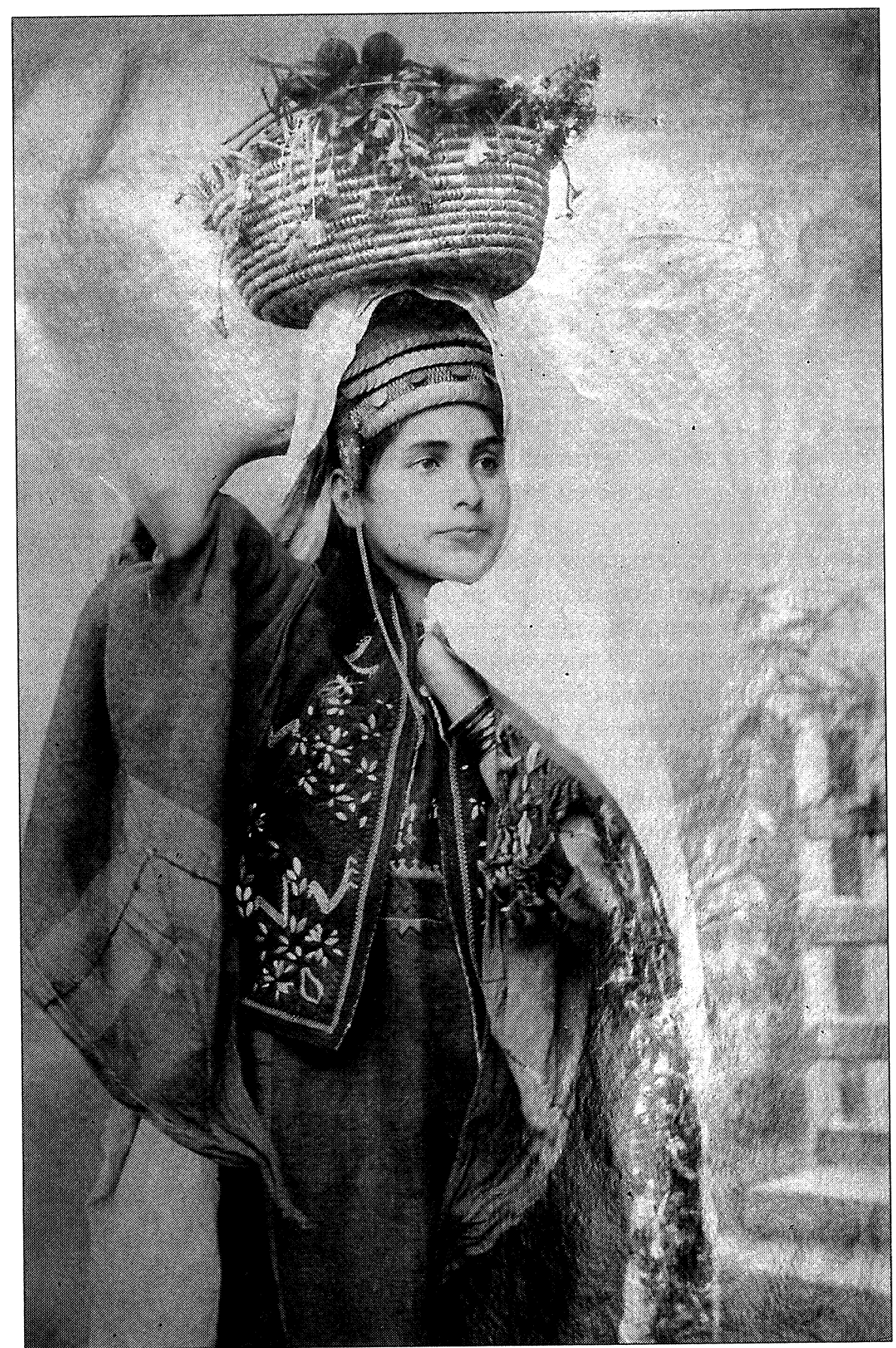

FIG. 2.-Colección Joan Naranjo. Barcelona. 


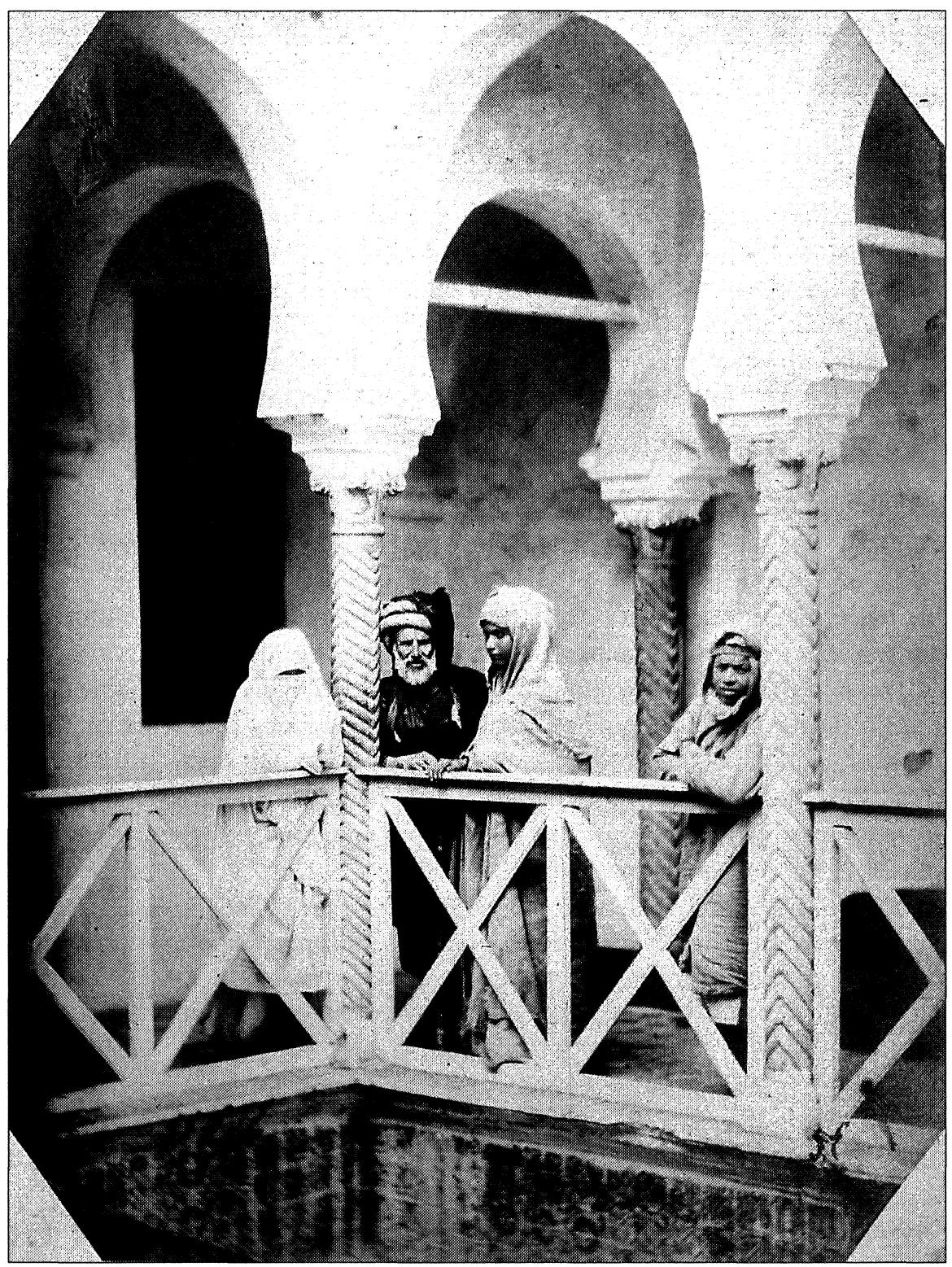

FIG. 3.-Colección Joan Naranjo. Barcelona. 
meses de visitar el país, en su catálogo L'Algérie Photographique, de 1859, había registradas más de 450 fotografías de Argelia; lo que nos da una idea de la intensa producción que alcanzó. A. Frish realizó unas excelentes fotografías de carácter 'antropológico' sobre los indios del Amazonas. En algunas de sus imágenes descontextualiza al personaje retratado mediante retoques, dejando los fondos blancos para así resaltar el carácter de los aborígenes. Sus fotografías 'antropológicas' fueron expuestas en la Exposición Universal de París de 1867. John Thomson, uno de los más famosos fotógrafos de viajes del siglo XIX, estuvo durante diez años fotografiando el lejano Oriente, Camboya, Malasia y China. Thomson llevó a cabo un excelente trabajo 'etnográfico' que apareció publicado bajo el título de Illustrations of China and Its People (1873-1874). Wilhelm Hammerschmidt está considerado como uno de los mejores fotógrafos establecidos en Egipto. Son de destacar sus fotografías sobre los diferentes tipos nativos, oficios artesanos y vida cotidiana. Sus fotografías de vistas de Egipto y el Cairo y sus 'tipos' egipcios fueron expuestas en la Société Française de Photographie (1862 y 1863) y sus imágenes sobre la vida cotidiana de Egipto y Siria, en la Exposición Universal de París (1867). Rafael Castro Ordóñez ${ }^{11}$ participó en la última gran expedición romántica que el gobierno español, bajo el reinado de Isabel II, envió al Nuevo Mundo en 1862. Castro Ordóñez visitó numerosos países donde llevó a cabo una excelente labor fotográfica, sobre todo apreciable en las imágenes que realizó de los indios Mapuches (Chile), estas imágenes tienen un marcado carácter científico; utilizó fondos neutros, rechazó las poses 'artísticas' y recurrió a la sistematización de las poses, creando una cierta tipología, posiblemente para llevar a cabo posteriores comparaciones entre los diferentes 'tipos' fotografiados.

Como podemos observar, las primeras fotografías antropológicas o etnográficas no fueron realizadas por antropólogos, sino por una gran variedad de observadores: F. Frith (fotógrafo comercial), Desiré Charnay (arqueólogo), Rafael Castro Ordóñez (ilustrador), J. T. Barclay (médico y misionero), etc.

Los antropólogos, en esa época, no hacían trabajo de campo, se dedicaban a recopilar, examinar y comparar las informaciones que recibían de las diferentes oficinas coloniales, de las misiones, de los viajeros, o las que les podían suministrar los fotógrafos de sus viajes. Muchas de las fotografías que realizaron estos viajeros tienen un carácter 'etnográfico',

11 Rafael Castro Ordóñez fue el fotógrafo de la expedición y cronista de la revista El Museo Universal de Madrid, donde enviaba los artículos y fotografías de los diferentes lugares que visitaba. 
pero contribuyeron, al mismo tiempo, a fomentar los estereotipos ${ }^{12}$ (figura 3), dado que había una avidez por conocer las partes más lejanas del mundo, las más 'exóticas'. Este hecho generó que hubiese una gran difusión comercial de las fotografías de estos lugares remotos en las ciudades más importantes. El artículo que publicó Once a Week en 1861 nos puede dar una idea de la importancia de este fenómeno: "Todos nosotros hemos visto los Alpes y conocemos Chamonix [...] aunque nunca hemos afrontado los horrores del Canal de la Mancha [...] Hemos atravesado los Andes, ascendido al Tenerife, entrado en Japón [...] en pocas palabras, hemos observado a través de una lente de tres pulgadas [...] este mundo malvado, pero bello" ${ }^{13}$.

Muchas de estas imágenes eran realizadas por estudios comerciales y vendidas a los viajeros/turistas; muchas de las veces respondían a criterios preestablecidos, basados en una visión idealizada y romántica. Es bastante frecuente ver cómo los mismos fotógrafos se disfrazaban, adoptando el 'rol' de los propios 'tipos' que ellos fotografiaban.

Los antropólogos se encontraron con que el material que recibían no era lo bastante homogéneo para realizar un estudio de las diferentes razas humanas. Este problema queda bien patente en una carta de T. H. Huxley donde comentó: "Aunque ya existe un gran número de fotografías etnológicas, se pierde mucho de su valor al no haber sido tomadas uniformemente y con un plan bien estudiado. El resultado es que raramente son mesurables o comparables con otras y que fallan en dar aquella información precisa respecto a las proporciones y la conformidad del cuerpo" ${ }^{14}$.

Durante la década de 1860 hubo una búsqueda, sobre todo por parte de los antropólogos físicos, para dar una base científica a las fotografías que se obtenían de los diferentes tipos que configuran la raza humana. A partir de entonces, se empezaron a desarrollar diferentes métodos que permitieron a los fotógrafos obtener datos y medidas morfológicas 'fidedignas' y 'estandarizadas' para su posterior comparación con el resto de fotografías. La mayor parte de estos métodos parten de los ideados por T. H. Huxley y J. Lamprey, si bien uno de los más utilizados en fotografía antropométrica fue el de realizar una vista de frente y otra de perfil, sistema que, posteriormente, Alphonse Bertillon pondría al servicio de la

12 Juan NARANJO, art. cit.

13 Citado por Susan SonTAG, Sobre la Fotografia (Barcelona: Edhasa, 1981).

14 Carta de T. H. Huxley a Lord Granville (diciembre de 1869. Citada por Frank SPENCER, "Some Notes on the Attemp to Photography to Anthropomery during teh Second Half Nineteenth Century", Anthropology Today (1869). Ver en Elizabeth Edwards (ed.), Antbropology and Photography 1860-1920 (London \& New Haven: Yale University Press). 
fotografía judicial y que persiste hassta nuestros días. Hasta bien iniciado el siglo xx se realizaron infinidad de fotografías antropométricas - por los diferentes sistemas- aunque de la mayor parte de ellas se desconoce el autor. Las fotografías eran normalmente tomadas en los estudios de los fotógrafos, solían utilizar modelos que estaban de paso por las grandes ciudades, marineros, personajes de circo, presidiarios, miembros de las delegaciones de otros países o aborígenes que se presentaban en las diferentes exposiciones internacionales, coloniales o etnográficas.

Dentro de la fotografía antropométrica cabe destacar la labor realizada por el antropólogo inglés J. Lamprey, quien, además de desarrollar un método de medición morfométrica, hizo innumerables fotografías. También hay que citar los trabajos del naturalista francés Philippe Potteau ${ }^{15}$ que, a partir de 1860, inició una colección de retratos antropológicos, para la que tomó como modelos a los miembros de las embajadas orientales en París, así como a gran cantidad de tipos europeos y africanos; recurrió con frecuencia a la sistematización mediante la utilización del retrato de frente y de perfil. También fotografió cráneos y algunos aborígenes durante un viaje que realizó a Argelia en 1862.

Carl Dammann, a principios de 1870, hizo unas interesantes fotografías por encargo de la Berliner Gesellschaftf für Anthropologie, Ethnologie und Urgeschichte, y posteriormente publicó un interesante álbum titulado Anthropologish-Ethnologisches Album in Photographien (1873-1876). El álbum contiene 600 imágenes ordenadas por regiones geográficas; cada página va acompañada por breves encabezamientos donde se resume el tipo racial y cultural. Dammann, en realidad, se dedicó en esta obra a copiar las fotografías realizadas por otros fotógrafos; el álbum tuvo una gran resonancia y ganó una medalla de bronce en la Exposición Internacional de Viena (1873). No fue, sin embargo, el primero de carácter etnográfico publicado, ya que en 1868 apareció la obra The People of India, proyecto iniciado en 1856 por Lord Canning e interrumpido por la rebelión india. La documentación fue realizada por los oficiales del servicio indio y editada en ocho volúmenes

En Rusia, bajo los auspicios de la Sociedad Geográfica Imperial Rusa, se produjo una intensificación de la investigación científica, etnográfica y geográfica. En 1872, en las actas de la sociedad geográfica, se publicaron instrucciones especiales para los fotógrafos respecto a la distinción entre fotografía fisionómica y etnográfica. Durante esta época, se publicaron varios álbumes de especial interés, como el Turkestan Album, realizado

15 Philippe Potteau, parece ser que fue el primer fotógrafo antropológico que trabajó bajo esa denominación en el Museo de Historia Natural de París. 
por G. N. Nekhoroshev y editado en 1872. En él no sólo se mostraban los diferentes tipos regionales y domésticos, sino también costumbres religiosas y labores autóctonas. Stasov escribió sobre esta colección: "ni una sola parte de nuestro estado ha sido previamente presentada tan sistemáticamente ni tan a fondo" ${ }^{16}$. Igualmente, cabe destacar los álbumes publicados por Losif Kordysh, fotógrafo conocido por sus composiciones etnográficas y miembro de la Sociedad Geográfica: Album of Russian Costume (1875) y Etbnographic Album of Liffle Russia (1870-1880). En Francia, el polifacético antropólogo y geógrafo Príncipe Roland Bonaparte realizó una interesante labor en el ámbito de la fotografía antropológica. En 1883 publicó el álbum Peaux Rouges, con fotografías antropométricas de los indios Omaha (fig. 4) instalados en el jardín de aclimatación en París; en 1884 participó en una expedición a Laponia, donde llevó a cabo una importante documentación fotográfica. Ese mismo año publicó Les Habitants de Suriname, colección de retratos realizados durante la Exposición Colonial de Amsterdam (1883).

A finales del siglo XIX se inician una serie de proyectos impulsados por mecenas o políticos interesados en preservar la historia de sus países, al mismo tiempo que la de otras culturas, este sería el caso de los interesantes trabajos realizados por Sir Benjamin Stone, Albert Kahn y Edward Sheriff Curtis. En 1897, Sir Benjamin Stone, industrial y parlamentario de Birmingham, fundó la National Photographic Record Association con el fin de documentar las ceremonias y fiestas rurales inglesas, que estaban en vías de extinción. Stone realizó innumerables fotografías en una línea folclórica y escribió: "Cada aldea tiene una historia que podría preservarse por medio de la cámara" ${ }^{17}$. Esa idea quedó plasmada en el libro, aparecido en 1906, Sir Bejamin Stone Pictures. Vol. I, Festivals, Ceremonies and Customs, donde se reproducen gran cantidad de las fotografías que había realizado, junto a una descripción de las fiestas, ceremonias y costumbres.

En 1909, el acaudalado banquero y mecenas francés Albert Khan inició uno de los proyectos más ambiciosos de los efectuados hasta el momento, al crear Archives de le Planete. Durante sus veintidós años de existencia, se tomaron 72.000 placas autocromas y 170.000 metros de film. Las numerosas expediciones que organizó dieron la vuelta al mundo y recopilaron una amplia y valiosa documentación, donde se recogen múltiples aspectos de la vida cotidiana, economía, religión, arte, costumbres, transporte, etc. Los operadores del archivo, dirigidos por Jean Brunhes,

16 Citado por Elena Barkhatova, "Realism and Document. Photography as Fact", Photograpby in Rusia 1840-1940 (London: Thames and Hudson, 1992).

17 Citado por Susan SonTAG, op. cit. 


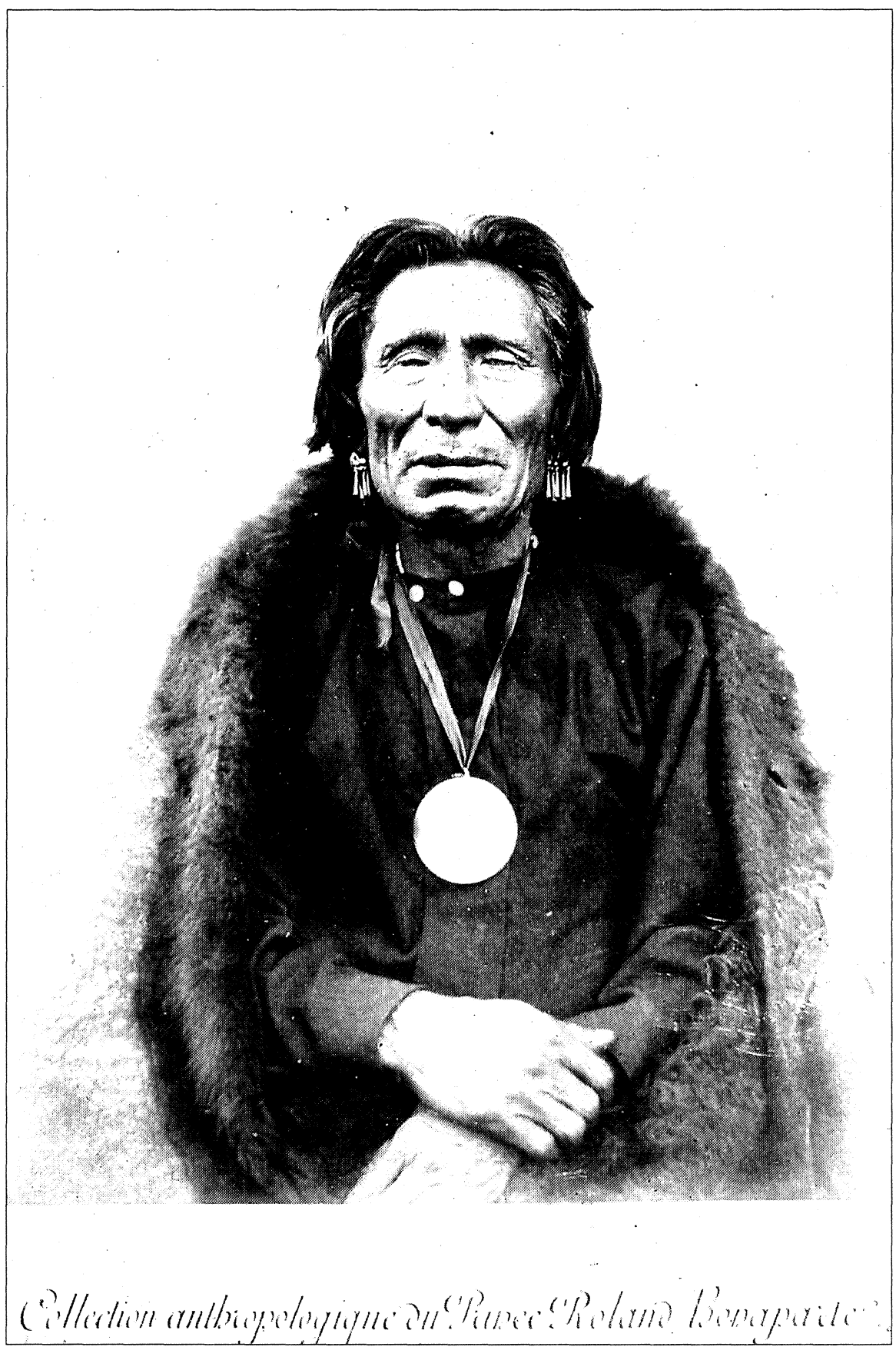

FIG. 4.-Shoudé Nasi. "Fumée Jaune”. Indios Omaha. Fondo Roland Bonaparte, 1883. Fototeca Musée de l'Homme. París. 
uno de los promotores de la geografía humana, fueron Auguste Leon, Leon Busy, Paul Castelnau, Georges Chevalier, Fernand Cuville, Roger Dumas, Frederic Gadmer y Stephane Passet; estos tres últimos también fueron operadores cinematográficos. La gran importancia de este archivo no estriba tanto en la cantidad de material que llegó a recopilar como en su gran interés documental y etnográfico, y sobre todo, en que fue uno de los primeros grandes inventarios efectuados en color por el procedimiento autocromo.

Edward Sheriff Curtis, fotógrafo y etnógrafo aficionado, recopiló la más extensa e impresionante documentación gráfica sobre los indios norteamericanos. Dedicó a su proyecto mas de treinta años y reunió unas 40.000 fotografías y una valiosa información sobre sus canciones, leyendas, tradiciones, etc. E. S. Curtis pudo hacer este trabajo porque llegó a convivir durante largos periodos de tiempo con las aproximadamente ochenta tribus que estudiaba, participando en sus ritos, fiestas, etc. Este esfuerzo compilador fue financiado en gran medida por el banquero J. P. Morgan y salió a la luz en una monumental publicación de veinte volúmenes, bajo el título The North American Indians (1907-1930). En la misma línea de E. S. Curtis, Robert Flaherty trabajó con los inuit, esquimales del Ártico canadiense. Al principio, sus fotos seguían las pautas de la fotografía expedicionaria, pero a medida que fue profundizando en el contacto con los inuit, consiguió retratar con gran fuerza y expresión las características de este pueblo. También es conocido como uno de los padres del cine documental por las películas que rodó sobre el mismo grupo ártico.

Hemos visto cómo a lo largo del siglo xIX coexisten dos tipos de fotografías, las fotografías antropológicas y las fotografías de interés antropológico. Es difícil discernir cuál de estas dos formas de concebir las imágenes nos puede aportar más información sobre el sujeto de análisis. No obstante, tanto las fotografías antropológicas como las 'otras' son una importante fuente de estudio y de análisis, tanto para la historia de la fotografía como de la antropología o de la interrelación entre ambas. 
La relación entre fotografía y antropología a lo largo de la historia, especialmente en el siglo XIX, ha sido intensa. Se pueden distinguir dos clases de fotografías en relación con la antropología: las fotografías antropológicas y las fotografías con interés antropológico; su estudio es hoy una importante fuente de conocimiento y análisis, tanto para la historia de la fotografía como de la antropología o de la relación entre ellas.

Although the relationship between photography and anthropology has always been intense, it was especially so in the 19th century. Two types of photographs provide an example: those that are in themselves pieces of anthropological information and those that have anthropological interest. Either type is an important source of information for the history of anthropology, the history of photography and the connection between the two. 